\title{
Expression of cyclooxygenase-2, peroxiredoxin I, peroxiredoxin 6 and nuclear factor- $\kappa B$ in oral squamous cell carcinoma
}

\author{
EUN-YOUNG LEE ${ }^{1}$, JI-YEON KANG $^{2}$ and KYOUNG-WON KIM ${ }^{1}$ \\ ${ }^{1}$ Department of Oral and Maxillofacial Surgery, College of Medicine and Medical Research Institute, \\ Chungbuk National University, Cheongju, Chungbuk 361-711; ${ }^{2}$ Department of Oral and Maxillofacial Surgery, \\ Dongtan Sacred Heart Hospital, Hallym University, Hwaseong, Gyeonggi 445-170, Republic of Korea
}

Received October 16, 2014; Accepted July 16, 2015

DOI: $10.3892 / 01.2015 .3705$

\begin{abstract}
Tumor development and progression are multistep processes that involve local tumor growth and invasion, followed by metastasis. The aggressiveness of the tumor is the major determinant of the mortality of oral cancer patients. The present study investigates whether the expression levels of cyclooxygenase-2 (COX-2), nuclear factor- $\kappa \mathrm{B}(\mathrm{NF}-\kappa \mathrm{B})$, peroxiredoxin 1 (PRDX1) and PRDX6 are associated with the development, proliferation, differentiation and recurrence of oral squamous cell carcinoma (OSCC). The mRNA expression levels of COX-2, NF- $\kappa \mathrm{B}, \mathrm{PRDX} 1$ and PRDX6 were examined in 50 OSCC specimens and 19 normal oral mucosae by quantitative polymerase chain reaction (qPCR). qPCR analysis showed that the mRNA levels of COX-2 in OSCC were significantly higher than those in the normal oral mucosae $(\mathrm{P}=0.021)$. The expression levels of PRDX1 in high-stage tumors (T3 and T4) were significantly elevated compared with those in low-stage tumors (T1) $(\mathrm{P}=0.047)$. Additionally, the expression levels of $\mathrm{NF}-\kappa \mathrm{B}$ in the high-grade tumor were significantly elevated compared with those in the low-grade tumors $(\mathrm{P}=0.030)$. Overall, it was indicated that the expression of COX-2 is strongly associated with the development of OSCC. Moreover, the enhanced expression of PRDX1 and NF- $\kappa \mathrm{B}$ may function in the progression of OSCC, which serves as a useful marker for prognosis in patients with oral cancer.
\end{abstract}

\section{Introduction}

Oral squamous cell carcinoma (OSCC) is a devastating disease, which affects humans. Despite the development

Correspondence to: Professor Ji-Yeon Kang, Department of Oral and Maxillofacial Surgery, Dongtan Sacred Heart Hospital, Hallym University, 40 Seokwoo-dong, Hwaseong, Gyeonggi 445-170, Republic of Korea

E-mail:ddskj@hallym.ac.kr

Key words: cyclooxygenase-2, peroxiredoxin I, peroxiredoxin 6, nuclear factor- $\kappa \mathrm{B}$, oral squamous cell carcinoma, polymerase chain reaction of surgical techniques and prosthetic repair, defects in the facial structures lead to severe aesthetic and functional problems (1-4). Uncontrollable and persistent loco-regional and distant recurrences with invasive disposition result in a low overall long-term survival rate. Thus, the valuable predictive factors of OSCC are required to prevent the tumorigenesis, progression and recurrence of the disease $(5,6)$. The present study investigated the expression levels of cyclooxygenase-2 (COX-2), peroxiredoxin 1 (PRDX1), PRDX6 and nuclear factor- $\kappa \mathrm{B}(\mathrm{NF}-\kappa \mathrm{B})$, which have previously been found to be highly expressed in various neoplasms (7).

COX is the rate-limiting enzyme in the conversion of arachidonic acid to prostaglandins (PGs) of which two isoforms, COX-1 and COX-2, have been described (8). COX-1 is constitutively expressed in a number of tissues and generates the PGs necessary for normal physiological function (7). Although COX-2 cannot normally be detected, proinflammatory or mitogenic stimuli cause its rapid induction $(9,10)$. Studies have indicated that COX-2 is involved in the process of carcinogenesis via a range of different mechanisms, including angiogenesis, cell proliferation and the prevention of apoptosis. Elevated COX-2 expression has been noted in several human malignancies, including colonic, breast, gastric, bronchial, esophageal and prostatic carcinomas, and head and neck cancers (11).

The PRDX antioxidant protein family is found in a large range of species and is important in the protection of cells against oxidants. Since 1998, the crystal structures of six PRDXs in mammals have been published, including four typical 2-Cys PRDXs (PRDX1, PRDX1I, TryP and AhpC), one atypical 2-Cys PRDX (PRDX V) and one 1-Cys PRDX (PRDX6) (12). This endogenous defense system is highly expressed in certain cancers. The overexpression of PRDX1 has been noted in follicular thyroid neoplasms, thyroiditis, lung cancer, malignant mesothelioma and breast cancer (13-16). Furthermore, PRDX2, 3, 5 and 6 levels were shown to be increased in malignant mesothelioma, while PRDX2 and 3 were overexpressed in breast cancer specimens compared with normal tissues $(14,16)$. The proliferation-associated gene (Pag), human PRDX1, was first isolated by the differential screening of cDNA libraries formed from untransformed and ras-transformed human mammary epithelial cells. As the proliferation of these cells stops during the commitment 
phase of differentiation, the higher Pag expression levels were correlated with cell proliferation (17). Also, PRDX1 takes part in the growth factor and tumor necrosis factor- $\alpha$ (TNF- $\alpha$ ) signaling cascades by regulating the intracellular concentration of $\mathrm{H}_{2} \mathrm{O}_{2}$ (18). These data indicate that the activity of PRDX1 may be associated with not only proliferation, but also the formation of reactive oxygen species (ROS), which participate in carcinogenesis in all stages, including initiation, promotion and progression (19).

$N F-\kappa B$ is found in an inactive form in the majority of cells. Active $\mathrm{NF}-\kappa \mathrm{B}$ complexes are dimers of a variety of combinations of the Rel family of polypeptides, consisting

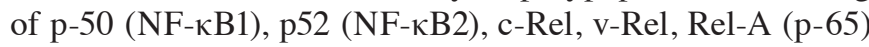
and Rel-B. In resting cells, retention of $\mathrm{p}-50$ and $\mathrm{p}-65$ heterodimers in the cytoplasm and their binding to the inhibitor $\kappa \mathrm{B}(\mathrm{I} \kappa \mathrm{B})$ proteins, blocks the nuclear translocation of $\mathrm{NF}-\kappa \mathrm{B}(18,20,21)$. I $\kappa \mathrm{B}$ degraded when it is phosphorylated by $\mathrm{I} \kappa \mathrm{B}$ kinase in response to a wide range of carcinogens and growth stimuli, including cigarette smoke, ultraviolet radiation, chemical carcinogens, epidermal growth factor receptor (EGFR), TNF- $\alpha$ and other cytokines $(14,22,23)$. $\mathrm{NF}-\kappa \mathrm{B}$ that has been liberated enters the nucleus and transactivates the expression of a number of significant oncogenes and proinflammatory cytokines, including c-myc, cyclin D1, B-cell lymphoma (Bcl)-XL, Bcl-2, Cox-2, survivin, matrix metalloproteinase-9; vascular endothelial cell growth factor, and interleukin (IL)-1, 6 and 9, whose functions are closely associated with abnormal cancer cell proliferation, survival and invasion $(18,20,21)$. The constitutive activation of $\mathrm{NF}-\kappa \mathrm{B}$ occurs in numerous types of malignancies, including head and neck SCC, and is associated with the aggressive phenotype of these tumors $(18,20,24)$.

During the last few years, studies on COX-2, PRDX1, PRDX6 and NF- $\kappa \mathrm{B}$ have been performed in OSCC, but these studies have relied on qualitative immunohistochemistry to assess the levels of protein. This type of test can be subject to interobserver variability. In the present study, the expression of COX-2, PRDX1, PRDX6 and NF-кB in OSCC was quantitatively evaluated using quantitative polymerase chain reaction (qPCR), and to the best of our knowledge, this is the first study of its type in OSCC.

\section{Patients and methods}

Patients and samples. A total of 50 OSCC tissues from 35 males and 15 females, with a mean age of 61 years (range, 35-82 years), were obtained during surgery or at biopsy in the Department of Oral and Maxillofacial Surgery and Otolaryngology, Chungbuk National University Hospital, (Cheongju, South Korea). The samples were classified in terms of the patient's age and gender, the primary site, the $\mathrm{T}$ stage of tumor size, the grade of histological cell differentiation, the presence of a primary or recurrent tumor, and the administration of prior chemotherapy at the time of obtaining the samples. $\mathrm{T}$ staging and histological grade were assessed according to the tumor-node-metastasis staging by the American Joint Committee on Cancer (Table I) (25). Additionally, 19 normal buccal mucosa tissues were obtained from healthy non-cancer patients with consent during minor oral surgical procedures. Each sample was examined histopathologically, and only those
Table I. Clinical and pathological features of patients with oral squamous cell carcinoma.

\begin{tabular}{lc}
\hline Parameter & Value \\
\hline Gender, $\mathrm{n}$ & \\
Male & 35 \\
Female & 15 \\
Age, years & $60.57 \pm 9.98$ \\
Stage, $\mathrm{n}$ & \\
T1 & 9 \\
T2 & 13 \\
T3 & 2 \\
T4 & 26 \\
Differentiation, $\mathrm{n}$ & \\
Well & 39 \\
Moderate & 8 \\
Poor & 3 \\
Tumor presence, $\mathrm{n}$ & \\
Primary & 44 \\
Recurrence & 6 \\
Chemotherapy, $\mathrm{n}$ & \\
No prior chemotherapy & 36 \\
Prior chemotherapy & 14 \\
\hline
\end{tabular}

that consisted of normal squamous epithelial cells were subsequently analyzed. Samples were snap-frozen in liquid nitrogen immediately after harvest and stored at $-70^{\circ} \mathrm{C}$ until RNA extraction. This study was approved by the Institutional Review Board of Chungbuk National University Hospital.

RNA extraction and reverse transcription. Total RNA was isolated from the tissues with TRIzol reagent (Invitrogen Life Technologies, Carlsbad, CA, USA) according to the manufacturer's instructions. cDNA was then prepared from $1 \mu \mathrm{g}$ total RNA by random priming using a First-Strand cDNA Synthesis kit (Amersham Biosciences Europe GmbH, Freiburg, Germany) according to the manufacturer's instructions.

$q P C R$. To quantify the expression levels of COX-2 (Fig. 1), PRDX1 (Fig. 2), PRDX6 (Fig. 3) and NF-кB (Fig. 4), qPCR amplification was performed using the Rotor Gene 3000 (Corbett Research, Mortlake, Australia) PCR machine. qPCR assays were performed using SYBR Premix EX Taq (Takara Bio Inc., Otsu, Japan) in a micro reaction tube (Corbett Research). The PCR was performed with a final volume of $10 \mu 1$, the reaction mixture consisting of $5 \mu$ l of 2 X SYBR Premix EX Taq buffer, $0.5 \mu \mathrm{l}$ of each of $5^{\prime}$ and $3^{\prime}$ primer $(10 \mathrm{pmol} / \mu \mathrm{l})$ and $1 \mu \mathrm{l}$ of sample cDNA.

For amplification, the following primers were used: COX-2, forward, 5'-CCATGGGGTGGACTTAAA-3' and reverse, 5'-ACAGCAAACCGTAGATGC-3' (186 bp); PRXDX1, forward, 5'-CCAACTTCAAAGCCACAG-3' and reverse, 5'-GTCTGATACCAAAGGAATG-3' (284 bp); PRDX6, forward, 5-CTTTGAGGCCAATACCACCG-3 and reverse, 5-AGATGGTCCTCAACACTGTC-3 (201 bp); and NF-кB, 


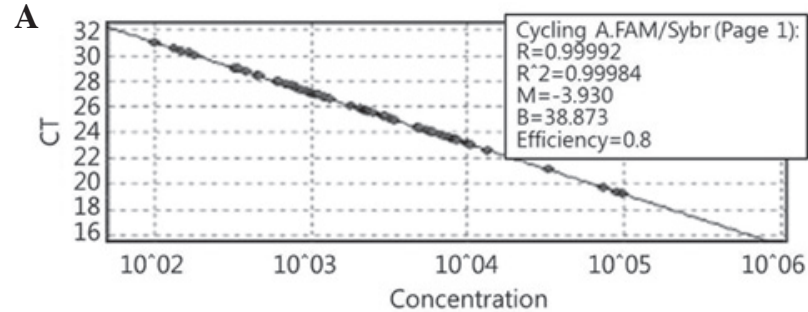

B

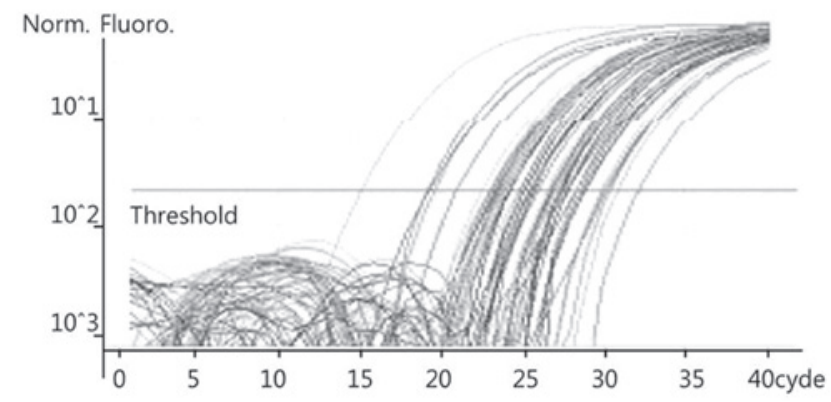

C

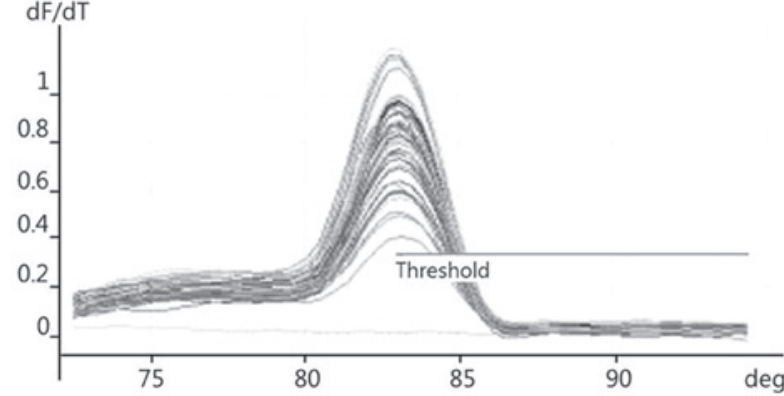

Figure 1. Examples of Rotor Gene 3000 printouts showing detection of COX-2 mRNA by qPCR assay. (A) Samples of known concentration and tissue cDNA were detected by qPCR. (B) Fluorescent signals of both 10 -fold serial dilutions of sample with known concentration and tissue cDNA were detected by qPCR. (C) Melting curves of amplified COX-2 were plotted COX-2, cyclooxygenase 2; qPCR, quantitative polymerase chain reaction; $\mathrm{CT}$, cycle threshold.

forward, 5'-AAGACCCACCCCACCATCAA-3' and reverse, 5'-AAACTGTGGATGCAGCAGCGGTC-3' (173 bp). The products were purified using a QIAquick Gel Extraction kit (Qiagen, Hilden, Germany), quantified by spectrophotometer (MBA2000; Perkin Elmer Inc., Walther, MA, USA) and the product sequences confirmed by automated laser fluorescence sequencer (ABI PRISM 3100 Genetic Analyzer; Applied Biosystems Life Technologies, Foster City, CA, USA).

The known concentrations of the COX-2, PRDX1, PRDX6 and NF- $\mathrm{\kappa B}$ PCR products were serially diluted (10-fold) from $1 \mathrm{pg} / \mu 1$ to $0.1 \mathrm{fg} / \mu \mathrm{l}$, from $4 \mathrm{pg} / \mu 1$ to $0.4 \mathrm{fg} / \mu \mathrm{l}$, from $22.5 \mathrm{pg} / \mu 1$ to $2.5 \mathrm{fg} / \mu \mathrm{l}$, and from $10 \mathrm{pg} / \mu \mathrm{l}$ to $0.1 \mathrm{fg} / \mu \mathrm{l}$, respectively. The dilution series of the PCR products were used for establishing standard curves of the qPCR (Figs. 1A, 2A and 3A). The qPCR conditions were as follows: 1 cycle at $96^{\circ} \mathrm{C}$ for $1 \mathrm{~min}$, followed by 40 cycles of $96^{\circ} \mathrm{C}$ for $2 \mathrm{sec}, 56^{\circ} \mathrm{C}$ for $20 \mathrm{sec}$ and $72^{\circ} \mathrm{C}$ for $20 \mathrm{sec}$ for COX-2; 1 cycle at $95^{\circ} \mathrm{C}$ for $1 \mathrm{~min}$, followed by 40 cycles of $95^{\circ} \mathrm{C}$ for $10 \mathrm{sec}, 54^{\circ} \mathrm{C}$ for $15 \mathrm{sec}$ and $72^{\circ} \mathrm{C}$ for $20 \mathrm{sec}$ for PRDX1; 1 cycle at $95^{\circ} \mathrm{C}$ for $1 \mathrm{~min}$, followed by 40 cycles of $95^{\circ} \mathrm{C}$ for $10 \mathrm{sec}, 62.5^{\circ} \mathrm{C}$ for $15 \mathrm{sec}$ and $72^{\circ} \mathrm{C}$ for $20 \mathrm{sec}$ for PRDX6; and 1 cycle at $96^{\circ} \mathrm{C}$ for $1 \mathrm{~min}$, followed by 40 cycles of $96^{\circ} \mathrm{C}$ for $2 \mathrm{sec}$, $60^{\circ} \mathrm{C}$ for $20 \mathrm{sec}$ and $72^{\circ} \mathrm{C}$ for $20 \mathrm{sec}$ for NF-kB. The melting program was performed at $72-96^{\circ} \mathrm{C}$ for COX-2 and NF- $\kappa \mathrm{B}$, and
A

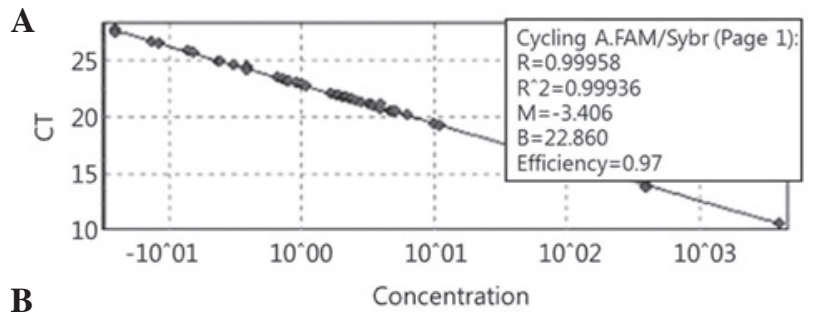

B

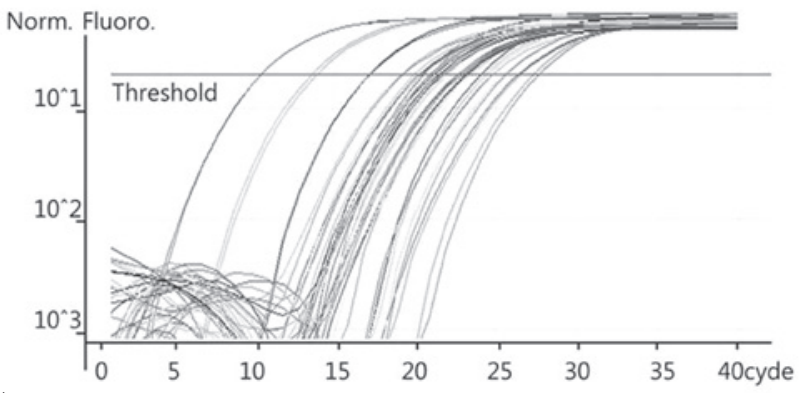

C

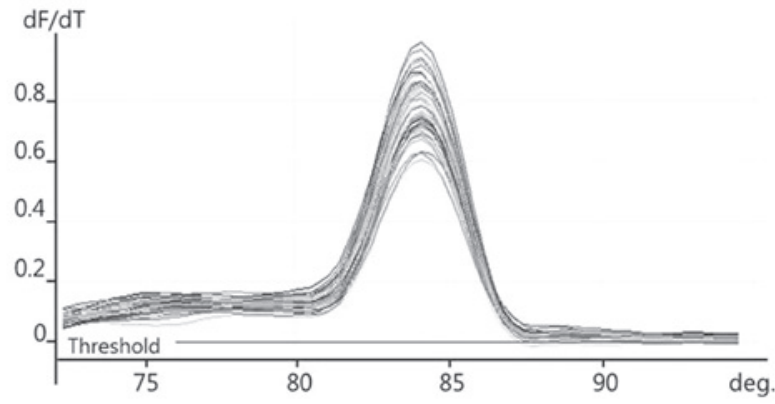

Figure 2. Examples of Rotor Gene 3000 printouts showing detection of PRDX1mRNA by qPCR assay. (A) Samples of known concentration and tissue cDNA were detected by qPCR. (B) Fluorescent signals of both 10-fold serial dilutions of sample with known concentration and tissue cDNA were detected by qPCR. (C) Melting curves of amplified PRDX1 were plotted. PRDX1, peroxiredoxin 1; qPCR, quantitative polymerase chain reaction; $\mathrm{CT}$, cycle threshold.

at $72-95^{\circ} \mathrm{C}$ for PRDX1 and PRDX6, with a heating rate of $1^{\circ} \mathrm{C}$ every $45 \mathrm{sec}$. Spectral data were captured and analyzed using Rotor-Gene Real-Time Analysis Software 6.0 Build 14 (Corbett Research) (Figs. 1B and C, 2B and C, and 3B and C).

Statistical analysis. The COX-2, PRDX1, PRDX6 and NF- $\mathrm{BB}$ mRNA expression levels of the OSCC tissues and normal oral mucosae were compared. The results were presented as the mean \pm standard deviation upon comparison. Histologically well-differentiated tumors were classified as low grade, while moderate- and poorly-differentiated tumors were classified as high grade. The correlations of COX-2, PRDX1, PRDX6 and NF- $\kappa \mathrm{B}$ mRNA expression levels with tumor size were assessed by Kruskal-Wallis test, and grade, recurrence and the previous administration of chemotherapy were assessed by the Mann-Whitney test. All analyses were performed with SPSS for windows (ver. 12.0.1; SPSS, Inc., Chicago, IL, USA), and P<0.05 was used to indicate a statistically significant difference.

\section{Results}

Comparison of COX-2, PRDX1, PRDX6 and NF- $\kappa B$ mRNA expression levels in OSCC and normal oral mucosa tissues. The COX-2 mRNA expression levels of 50 OSCC tissues 
Table II. COX-2, PRDXI, PRDX6 and NF-кB mRNA expression levels in OSCC tissues and normal oral mucosae.

mRNA expression, $\mathrm{pg} / \mathrm{ml}$

\begin{tabular}{lrcr}
\cline { 2 - 4 } Genes & OSCC $(\mathrm{n}=50)$ & Normal oral mucosae $(\mathrm{n}=19)$ & P-value \\
\hline COX-2 & $7.753 \pm 2.294$ & $2.179 \pm 0.464$ & 0.021 \\
PRDX1 & $10.962 \pm 1.641$ & $6.420 \pm 4.072$ & 0.218 \\
PRDX6 & $3.186 \pm 0.490$ & $3.460 \pm 0.595$ & 0.760 \\
NF-kB & $10.098 \pm 1.602$ & $8.979 \pm 1.097$ & 0.687
\end{tabular}

OSCC, oral squamous cell carcinoma; COX-2, cyclooxygenase 2; PRDX, peroxiredoxin; NF- $\mathrm{B}$, nuclear factor- $\kappa \mathrm{B}$.

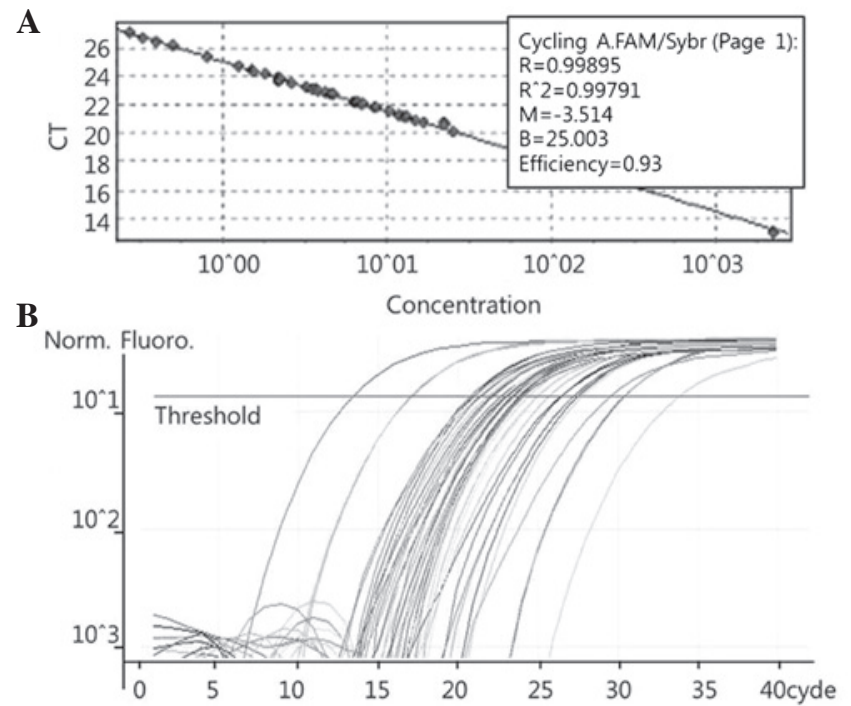

C

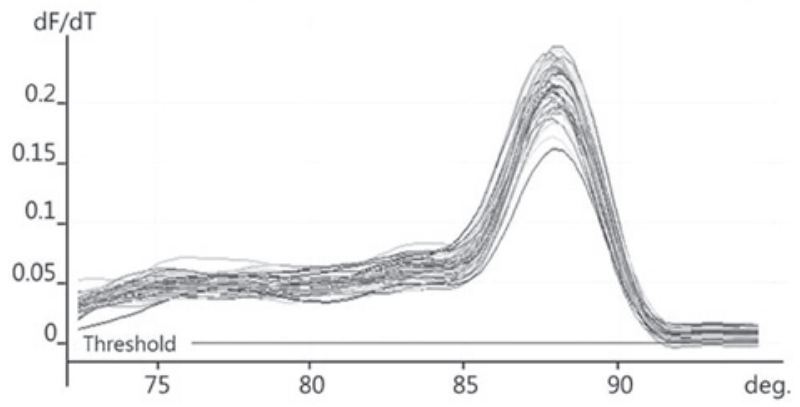

Figure 3. Examples of Rotor Gene 3000 printouts showing detection of PRDX6 mRNA by qPCR assay. (A) Samples of known concentration and tissue cDNA were detected by qPCR. (B) Fluorescent signals of both 10-fold serial dilutions of sample with known concentration and tissue cDNAs were detected by qPCR. (C) Melting curves of amplified PRDX6 were plotted. PRDX6, peroxiredoxin 6; qPCR, quantitative polymerase chain reaction; $\mathrm{CT}$, cycle threshold.

and 19 normal oral mucosa tissues were $7.753 \pm 2.294$ and $2.179 \pm 0.464 \mathrm{pg} / \mathrm{ml}$, respectively. The COX-2 mRNA expression levels in the OSCC tissues were significantly higher than that in the normal oral mucosa tissues $(\mathrm{P}=0.021)$ (Table II).

The PRDX1 mRNA expression levels of the 50 OSCC tissues and 19 normal oral mucosa tissues were $10.962 \pm 1.641$ and $6.420 \pm 4.072 \mathrm{pg} / \mathrm{ml}$, respectively. The PRDX1 mRNA expression levels were not significantly different between the OSCC tissues and the normal oral mucosa tissues $(\mathrm{P}=0.218)$ (Table II).
A

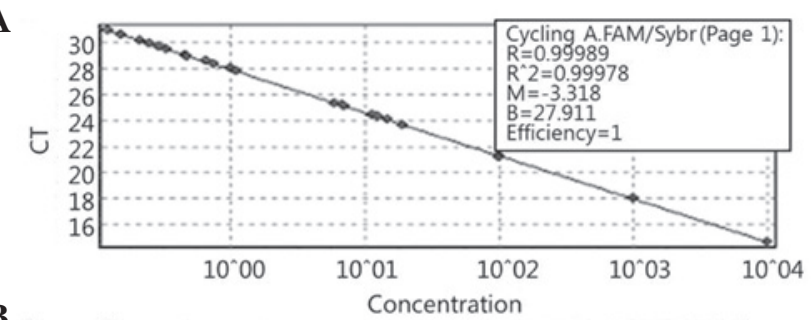

B

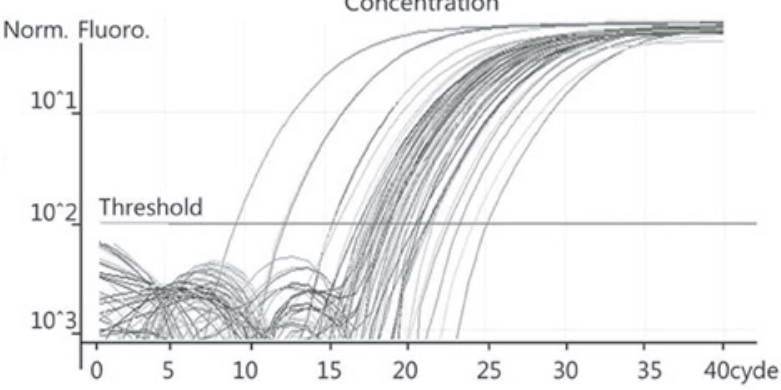

C

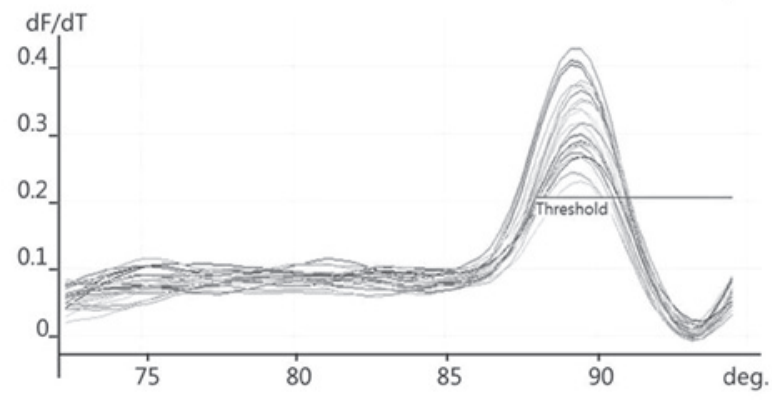

Figure 4. Examples of Rotor Gene 3000 printouts showing detection of NF- $\kappa$ B mRNA by qPCR assay. (A) Samples of known concentration and tissue cDNA were detected by qPCR. (B) Fluorescent signals of both 10-fold serial dilutions of sample with known concentration and tissue cDNA were detected by qPCR. (C) Melting curves of amplified NF- $\kappa \mathrm{B}$ were plotted. $\mathrm{NF}-\kappa \mathrm{B}$, nuclear factor- $\kappa \mathrm{B}$; qPCR, quantitative polymerase chain reaction; CT, cycle threshold.

The PRDX6 mRNA expression levels of the 50 OSCC tissues and 19 normal oral mucosa tissues were $3.186 \pm 0.490$ and $3.460 \pm 0.595 \mathrm{pg} / \mathrm{ml}$, respectively. The PRDX6 mRNA expression levels were not significantly different between the OSCC tissues and the normal oral mucosa tissues $(\mathrm{P}=0.760)$ (Table II).

The NF- $\kappa$ B mRNA expression levels of the 50 OSCC tissues and 19 normal oral mucosa tissues were $10.098 \pm 1.602$ and $8.979 \pm 1.097 \mathrm{pg} / \mathrm{ml}$, respectively. The NF- $\kappa \mathrm{B}$ mRNA expression levels were not significantly different between the OSCC tissues and the normal oral mucosa tissues $(\mathrm{P}=0.687)$ (Table II). 
Table III. COX-2, PRDXI, PRDX6 and NF- $\mathrm{B}$ mRNA expression level of OSCC tissues according to stage.

OSCC mRNA expression, pg/ml

\begin{tabular}{lccr}
\cline { 2 - 4 } Genes & Low-stage tumor $(\mathrm{T} 1)(\mathrm{n}=9)$ & High-stage tumor $(\mathrm{T} 3$ and $\mathrm{T} 4)(\mathrm{n}=28)$ & P-value \\
\hline COX-2 & $5.240 \pm 1.586$ & $12.511 \pm 2.778$ & 0.147 \\
PRDXI & $5.234 \pm 3.078$ & $13.981 \pm 2.509$ & 0.047 \\
PRDX6 & $2.290 \pm 0.771$ & $3.872 \pm 0.752$ & 0.288 \\
NF-kB & $2.373 \pm 0.965$ & $10.970 \pm 4.115$ & 0.147
\end{tabular}

Low stage: tumor size $\leq 2 \mathrm{~cm}$ (T1), high stage: tumor size $>4 \mathrm{~cm}$, invasion of adjacent structures $(\mathrm{T} 3,4)$. OSCC, oral squamous cell carcinoma; COX-2, cyclooxygenase 2; PRDX, peroxiredoxin; NF- $\kappa \mathrm{B}$, nuclear factor- $\kappa \mathrm{B}$.

Table IV. COX-2, PRDXI, PRDX6 and NF- $\kappa$ B mRNA expression level of OSCC tissues according to differentiation.

\begin{tabular}{|c|c|c|c|}
\hline \multirow[b]{2}{*}{ Genes } & \multicolumn{2}{|c|}{ OSCC mRNA expression, pg/ml } & \multirow[b]{2}{*}{ P-value } \\
\hline & Low-grade tumor (G1) $(\mathrm{n}=39)$ & High-grade tumor $(\mathrm{G} 2$ and G3) $(\mathrm{n}=11)$ & \\
\hline $\mathrm{COX}-2$ & $7.245 \pm 2.482$ & $10.469 \pm 6.887$ & 0.788 \\
\hline PRDXI & $9.848 \pm 1.907$ & $15.368 \pm 3.591$ & 0.171 \\
\hline PRDX6 & $3.036 \pm 0.532$ & $4.378 \pm 1.371$ & 0.343 \\
\hline $\mathrm{NF}-\kappa \mathrm{B}$ & $8.488 \pm 1.490$ & $17.218 \pm 5.228$ & 0.048 \\
\hline
\end{tabular}

Low-grade tumor, well-differentiated (G1); high-grade tumor, moderately-differentiated (G2) and poorly-differentiated (G3). OSCC, oral

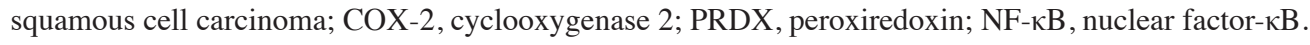

Table V. COX-2, PRDXI, PRDX6 and NF- $\kappa$ B mRNA expression levels of primary and recurrent tumors.

OSCC mRNA expression, pg/ml

\begin{tabular}{lccc}
\cline { 2 - 3 } Genes & Primary tumor $(\mathrm{n}=44)$ & Recurrent tumor $(\mathrm{n}=6)$ & P-value \\
\hline COX-2 & $5.547 \pm 1.824$ & $25.609 \pm 14.165$ & 0.439 \\
PRDXI & $10.908 \pm 1.813$ & $12.196 \pm 5.306$ & 0.850 \\
PRDX6 & $3.449 \pm 0.563$ & $2.468 \pm 1.122$ & 0.590 \\
NF- $\mathrm{B}$ & $11.042 \pm 1.859$ & $5.763 \pm 2.990$ & 0.189
\end{tabular}

OSCC, oral squamous cell carcinoma; COX-2, cyclooxygenase 2; PRDX, peroxiredoxin; NF- $\kappa \mathrm{B}$, nuclear factor- $\kappa \mathrm{B}$.

COX-2, PRDX1, PRDX6 and NF- $\kappa B$ mRNA expression levels of OSCC tissues according to the tumor stage. The COX-2, PRDX6 and NF- $\mathrm{NB}$ mRNA expression levels of the OSCC tissues did not show a significant correlation with tumor size $(\mathrm{P}=0.147, \mathrm{P}=0.288$ and $\mathrm{P}=0.147$, respectively; Table III). However, the PRDX1 mRNA expression levels of the 28 high-stage (T3 and T4) and 9 low-stage (T1) OSCC tissues were $13.981 \pm 2.509$ and $5.234 \pm 3.078 \mathrm{pg} / \mathrm{ml}$, respectively. The PRDX1 mRNA expression levels in the high-stage OSCC tissues were significantly higher than those in the low-stage OSCC tissues ( $\mathrm{P}=0.047)$ (Table III).

Comparison of COX-2, PRDX1, PRDX6 and NF- $\kappa B$ mRNA expression levels of OSCC tissues according to the degree of histological tumor cell differentiation. The COX-2,
PRDX1 and PRDX6 mRNA expression levels of the OSCC tissues did not show a significant correlation with tumor differentiation $(\mathrm{P}=0.788, \mathrm{P}=0.171$ and $\mathrm{P}=0.343$, respectively; Table IV). However, the NF- $\kappa \mathrm{B}$ mRNA expression levels of 11 high-grade (moderate- and poorly-differentiated) OSCC tissues and 39 low-grade (well-differentiated) OSCC tissues were $17.218 \pm 5.228$ and $8.488 \pm 1.490 \mathrm{pg} / \mathrm{ml}$, respectively. The $\mathrm{NF}-\kappa \mathrm{B}$ mRNA expression levels in the high-grade OSCC tissues were significantly higher than those in the low-grade OSCC tissues $(\mathrm{P}=0.048)$ (Table IV).

Comparison of COX-2, PRDX1, PRDX6 and NF- $\kappa B$ mRNA expression levels of OSCC tissues according to tumor recurrence. The COX-2, PRDX1, PRDX6 and NF- $\mathrm{B}$ mRNA expression levels of 44 primary OSCC tissues and 6 recurrent 
Table VI. COX-2, PRDXI, PRDX6 and NF-кB mRNA expression levels of OSCC tissues following chemotherapy.

OSCC mRNA expression, pg/ml

\begin{tabular}{lccr}
\cline { 2 - 4 } Genes & Prior chemotherapy $(\mathrm{n}=14)$ & No prior chemotherapy $(\mathrm{n}=36)$ & P-value \\
\hline COX-2 & $11.437 \pm 6.312$ & $6.600 \pm 2.349$ & 0.105 \\
PRDXI & $13.618 \pm 3.038$ & $10.068 \pm 2.044$ & 0.218 \\
PRDX6 & $3.596 \pm 0.834$ & $3.228 \pm 0.638$ & 0.364 \\
NF-kB & $10.944 \pm 2.258$ & $10.200 \pm 2.185$ & 0.290
\end{tabular}

OSCC, oral squamous cell carcinoma; COX-2, cyclooxygenase 2; PRDX, peroxiredoxin; NF- $\mathrm{B}$, nuclear factor- $\kappa \mathrm{B}$.

OSCC tissues did not show a correlation with tumor recurrence $(\mathrm{P}=0.439, \mathrm{P}=0.850, \mathrm{P}=0.590$ and $\mathrm{P}=0.189$, respectively, Table V). COX-2 level tended to be higher in the recurrent tumors, but this difference was not statistically significant.

Comparison of COX-2, PRDX1, PRDX6 and NF- $\kappa B$ mRNA expression levels of OSCC tissues according to the prior administration of chemotherapy. The COX-2, PRDX1, PRDX6 and $\mathrm{NF}-\kappa \mathrm{B}$ mRNA expression levels of 14 OSCC tissues previously administered chemotherapy and 36 OSCC tissues not administered chemotherapy were examined. There was no correlation with the administration of previous chemotherapy in each group $(\mathrm{P}=0.105, \mathrm{P}=0.218, \mathrm{P}=0.364$ and $\mathrm{P}=0.290$, respectively; Table 6).

\section{Discussion}

The identification of a biological marker that correlates with a specific tumor would provide more accurate information and enable molecular-targeted therapy. There are a number of potential molecular markers in OSCC that have drawn considerable interest.

Selective COX-2 overexpression has been found in head and neck, bronchial, breast, pancreatic, colon and gastric cancers. Particularly, a higher expression level of COX-2 has been identified in head and neck OSCC when compared with other cancers (11,26-29). Tumor specimens with confirmed cervical lymph node metastasis have a significantly higher level of COX-2 expression, as do advanced and poorly-differentiated head and neck SCCs. Peng et al noted the overexpression of COX-2 in N1-N3 tumors compared with N0 tumors in a series of 23 hypopharyngeal SCC cases (28). Shibata et al noted labeling indices of COX-2 that correlated with the histological grade of dysplasia, being highest for the severe dysplasias on four human OSCC cell lines (11). Another study also showed that COX-2 expression is involved in the regulation of cell proliferation and in the progression from normal tissue to SCC (30). One previous study by Tsujii and DuBois examined the association between apoptosis and COX-2, and found that COX-2 gene transfection into rat intestinal epithelial cells decreases the susceptibility of the cells to apoptosis and upregulates antiapoptotic Bcl-2 protein expression (31). Although the present study showed a good correlation between COX-2 mRNA expression and OSCC $(\mathrm{P}=0.021), \mathrm{COX}-2$ mRNA expression was not significantly correlated with other factors, such as tumor size, differentiation, recurrence and previous chemotherapy. COX-2 tended to be expressed at a higher level in recurrent tumors, although without a significant correlation (primary tumor $(\mathrm{n}=44), 5.547 \pm 1.824 \mathrm{pg} / \mathrm{ml}$; recurrent tumor $(\mathrm{n}=6), 25.609 \pm 14.165 \mathrm{pg} / \mathrm{ml} ; \mathrm{P}=0.439)$; this may be as the recurrent tumor group was small in number. In addition, it has been demonstrated that COX-2 overexpression has a critical period. Zhi et al noted that strong COX-2 expression was detected as early as the stage of dysplasia and invasive SCC, while being weakly expressed in the esophageal squamous epithelium (32). Kase et al demonstrated a peak of expression in high-grade dysplasia and carcinoma in situ, then a stable level with a declining trend (33). This may indicate that COX-2 facilitates tumorigenesis and progression in the early stage, independent of its expression level during progression.

Recently, a number of studies reported the increased expression of PRDX in several cancers, and since then, PRDX has received considerable attention as a novel marker. The studies using a PRDX1-knockout mouse indicated that PRDX1 in normal cells plays a direct role in tumor suppression by eliminating ROS and preventing oxidative damage, and PRDX1 expression was associated with the occurrence of malignant neoplasms (24). Similarly, consumedly proliferative tumor cells may express PRDX to protect themselves from oxidative damage. In malignant mesothelioma, PRDX1 and 6 are overexpressed, and tumor tissues with strong PRDX1 expression tended to experience an increased survival time (14). In primary bladder cancer, the PRDX1 and 6 expression levels were significantly elevated in non-progressed cases compared to the progressed cases (34). The overexpression of PRDX was also reported in human breast and lung cancer $(16,35)$. In OSCC, Yanagawa et al studied PRDX1 expression for the first time and found low PRDX1expression levels to be associated with larger tumor masses, lymph node metastases and poorly-differentiated tumors (36). This data is contrary to previous studies and the present result showing that the PRDX1 mRNA expression was elevated in larger tumors $(\mathrm{P}=0.047)$. Wen and Van Etten revealed that the paradoxical mechanism may be explained by the fact that Pag is a physiological inhibitor of c-Abl (37). c-Abl is an oncogene product with tyrosine kinase activity, which inhibits cell proliferation when activated by interacting with central elements controlling the cell cycle (38).

In a subsequent study, Yanagawa et al reported that PRDX1 expression was significantly associated with local and lymph 
node recurrence (39), which was in contrast to the present results. These results indicated that PRDX1 expression predicts a 2.8- to 2.9-fold more frequent incidence of recurrence. PRDX1 was originally isolated from proliferating cells and the overexpression of PRDX1 has been found in the proliferative type of tumors. Additionally, an elevated level of PRDX1 appears to abrogate the induced cell-cycle block and is able to act as a tumor suppressor through the reduction of ROS. Taken together, these data indicate that the PRDX expression level appears to vary depending on the type or stage of the cancer. It is also reasonable to suggest that the augmented expression of PRDX provides increased antioxidative activity, which may be responsible for its resistance to apoptosis as a tumor suppressor. An increased PRDX level in larger tumors would be a result of the antiapoptotic features of PRDX, providing a growth advantage to tumor cells.

$\mathrm{NF}-\kappa \mathrm{B}$ and $\mathrm{NF}-\kappa \mathrm{B}$ inducible gene activation has been detected in melanomas, prostate and breast cancer, and lymphoma $(40,41)$. In the head and neck, Takada et al showed enhanced I $\mathrm{KB}$ kinase (IKK) activity in carcinoma cells (42). Wolf et al revealed that IL-1 may function as an autocrine growth factor that is able to induce constitutive $N F-\kappa B$ activation (43), while Bancroft et al demonstrated that EGFR activation could result in $\mathrm{NF}-\kappa \mathrm{B}$ activation (44). Cumulative evidence in malignancies is compatible with the hypothesis that $\mathrm{NF}-\kappa \mathrm{B}$ is constitutively activated and has a major function in the pathogenesis of cellular and host alterations. $\mathrm{NF}-\kappa \mathrm{B}$ activation has been suggested to be a common pathway of widespread importance, and it has been suggested to be involved in promoting the expression of the phenotypic changes and genes involved in inhibition of programmed and therapeutic cell death, proliferation, tumorigenesis, angiogenesis, invasiveness and metastatic potential $(41,45)$. Nakayama et al noted that high expression levels of $N F-\kappa B$ (p65) and IKK contribute to malignant behavior and antiapoptotic activity in OSCC (45). Furthermore, molecular profiling has revealed that $\mathrm{NF}-\kappa \mathrm{B}$ may regulate a diverse repertoire of genes in SCC. Loercher et al obtained evidence with regard to the differential expression of known NF- $\mathrm{N}$-associated genes and found that $\mathrm{NF}-\kappa \mathrm{B}$ pathway modulation directly or indirectly alters a significant portion of these and other genes in the changed molecular profile, with malignant progression in a syngeneic model of SCC (41). This study confirmed that $\mathrm{I} \kappa \mathrm{B}-\alpha$ phosphorylation mutant expression suppressed $\mathrm{NF}-\kappa \mathrm{B}$ reporter and DNA binding activity, and modulated the protein and mRNA expression of a number of putative $\mathrm{NF}-\kappa \mathrm{B}$ target genes that are differentially-expressed in SCC, including Trp53, cyclin D1, IAP-1 and $\beta$-catenin. Consistent with the diversity and putative functions of a number of these genes, NF- $\mathrm{B}$ inhibition was noted to inhibit the proliferation, survival, migration, angiogenesis and tumorigenesis of cells. These results indicate that $\mathrm{NF}-\kappa \mathrm{B}$ is a significant modulator of the gene expression profile and malignant phenotype in SCC. In the present study, NF- $\mathrm{B}$ mRNA expression was correlated with the histopathological grade. The level was significantly elevated in the high-grade OSCC tissues $(\mathrm{P}=0.048)$, which agrees with the results previously published stating that the activation of $\mathrm{NF}-\kappa \mathrm{B}$ is associated with an aggressive tumor phenotype.
Generally, SCCs exhibit a range of clinical and histological features according to their stage of epithelial differentiation. Poorly-differentiated SCCs are known to grow at a faster pace and spread diffusely, leading to a poor prognosis. Furthermore, well-differentiated SCCs are chemotherapy- and radiotherapy-resistant. This suggests that $\mathrm{NF}-\kappa \mathrm{B}$ is a key molecular switch of the alterations in genotype and phenotype in the malignant progression of OSCC.

In conclusion, the expression of COX-2 is strongly associated with the development of OSCC. Moreover, the enhanced expression of PRDX1 and $\mathrm{NF}-\kappa \mathrm{B}$ may function in the progression of OSCC, which serves as a useful marker for the prognosis of patients with this disease.

\section{References}

1. Bianchi B, Ferri A, Ferrari S, et al: Reconstruction of lateral through and through oro-mandibular defects following oncological resections. Microsurgery 30: 517-525, 2010.

2. Thankappan K, Kuriakose MA, Chatni SS, Sharan R, Trivedi NP, Vijayaraghavan S, Sharma M and Iyer S: Lateral arm free flap for oral tongue reconstruction: An analysis of surgical details, morbidity, and functional and aesthetic outcome. Ann Plast Surg 66: 261-266, 2011.

3. Zeno HA, Sternberger SS, Tuminelli FJ, Billotte $M$ and Kurtz KS: Combination lower lip prosthesis retained by an intraoral component. J Prosthodont 22: 397-401, 2013.

4. Kawase-Koga Y, Mori Y, Saijo H, Hoshi K and Takato T: Reconstruction of a complex midface defect from excision of a squamous cell carcinoma, according to regional aesthetic units. Oral Surg Oral Med Oral Pathol Oral Radiol 117: e97-e101, 2014.

5. Chiesa F, Mauri S, Tradati N, Calabrese L, Giugliano G, Ansarin M, Andrle J, Zurrida S, Orecchia R and Scully C: Surfing prognostic factors in head and neck cancer at the millennium. Oral Oncol 35: 590-596, 1999.

6. Brinkman BM and Wong DT: Disease mechanism and biomarkers of oral squamous cell carcinoma. Curr Opin Oncol 18: 228-233, 2006.

7. Babu GS, Supriya AN, Raj Kumar NG and Swetha P: Tumor markers: An overview. J Orofac Sci 3: 87-95, 2012.

8. Sudbø J and Reith A: The evolution of predictive oncology and molecular-based therapy for oral cancer prevention. Int $\mathbf{J}$ Cancer 115: 339-345, 2005.

9. Kujubu DA, Reddy ST, Fletcher BS and Herschman HR: Expression of the protein product of the prostaglandin synthase-2/TIS10 gene in mitogen-stimulated Swiss 3T3 cells. J Biol Chem 268: 5425-5430, 1993.

10. Vane J: Towards a better aspirin. Nature 367: 215-216, 1994.

11. Shibata M, Kodani I, Osaki M, Araki K, Adachi H, Ryoke K and Ito H: Cyclo-oxygenase-1 and-2 expression in human oral mucosa, dysplasias and squamous cell carcinomas and their pathological significance. Oral Oncol 41: 304-312, 2005.

12. Wood ZA, Schröder E, Robin Harris J and Poole LB: Structure, mechanism and regulation of peroxiredoxins. Trends Biochem Sci 28: 32-40, 2003.

13. Yanagawa T, Ishikawa T, Ishii T, Tabuchi K, Iwasa S, Bannai S, Omura K, Suzuki H and Yoshida H: Peroxiredoxin I expression in human thyroid tumors. Cancer Lett 145: 127-132, 1999.

14. Kinnula VL, Lehtonen S, Sormunen R, Kaarteenahob WR, Kang SW, Rhee SG and Soini Y: Overexpression of peroxiredoxins I, II, III, V and VI in malignant mesothelioma. J Pathol 196: 316-323, 2002.

15. Chang JW, Jeon HB, Lee JH, Yoo JS, Chun JS, Kim JH and Yoo YJ: Augmented expression of peroxiredoxin I in lung cancer. Biochem Biophys Res Commun 289: 507-512, 2001.

16. Noh DY, Ahn SJ, Lee RA, Kim SW, Park IA and Chae HZ: Overexpression of peroxiredoxin in human breast cancer. Anticancer Res 21: 2085-2090, 2001.

17. Prosperi MT, Ferbus D, Karczinski I and Goubin G: A human cDNA corresponding to a gene overexpressed during cell proliferation encodes a product sharing homology with amoebic and bacterial proteins. J Biol Chem 268: 11050-11056, 1993.

18. Kang SW, Chae HZ, Seo MS, Kim K, Baines IC and Rhee SG: Mammalian peroxiredoxin isoforms can reduce hydrogen peroxide generated in response to growth factors and tumor necrosis factor-alpha. J Biol Chem 273: 6297-6302, 1998. 
19. Klaunig JE, Xu Y, Isenberg JS, Bachowski S, Kolaja KL, Jiang J, Stevenson DE and Walborg EF Jr: The role of oxidative stress in chemical carcinogenesis. Environ Health Perspect 106: 289-295, 1998.

20. Fujii J and Ikeda Y: Advances in our understanding of peroxiredoxin, a multifunctional, mammalian redox protein. Redox Rep 7: 123-130, 2002.

21. Ishii T, Yamada M, Sato H, Matsue M, Taketani S, Nakayama K, Sugita Y and Bannai S: Cloning and characterization of a $23-\mathrm{kDa}$ stress-induced mouse peritoneal macrophage protein. J Biol Chem 268: 18633-18636, 1993.

22. Liu M, Lawson G, Delos M, Jamart J, Ide C, Coche E, Weynand B, Desuter G, Hamoir M, Remacle M and Marbaix E: Predictive value of the fraction of cancer cells immunolabeled for proliferating cell nuclear antigen or Ki67 in biopsies of head and neck carcinomas to identify lymph node metastasis: Comparison with clinical and radiologic examinations. Head Neck 25: 280-288, 2003.

23. Matsumoto A, Okado A, Fujii T, Fujii J, Egashira M, Niikawa N and Taniguchi N: Cloning of the peroxiredoxin gene family in rats and characterization of the fourth member. FEBS Lett 443 246-250, 1999.

24. Neumann CA, Krause DS, Carman CV, Das S, Dubey DP, Abraham JL, Bronson RT, Fujiwara Y, Orkin SH and Van Etten RA: Essential role for the peroxiredoxin Prdx1 in erythrocyte antioxidant defence and tumour suppression. Nature 424: $561-565,2003$

25. Greene FL, Page D, Morrow M, et al (eds): Lip and oral cavity. In: AJCC Cancer Staging Manual. 6th edition. Springer, New York, pp23-32, 2002

26. Wolff H, Saukkonen K, Anttila S, Karjalainen A, Vainio H and Ristimäki A: Expression of cyclooxygenase-2 in human lung carcinoma. Cancer Res 58: 4997-5001, 1998.

27. Shamma A, Yamamoto H, Doki Y, Okami J, Kondo M, Fujiwara Y, Yano M, Inoue M, Matsuura N, Shiozaki $\mathrm{H}$ and Monden M Up-regulation of cyclooxygenase-2 in squamous carcinogenesis of the esophagus. Clin Cancer Res 6: 1229-1238, 2000.

28. Peng JP, Su CY, Chang HC, Chai CY and Hung WC: Overexpression of cyclo-oxygenase 2 in squamous cell carcinoma of the hypopharynx. Hum Pathol 33: 100-104, 2002.

29. Banerjee AG, Gopalakrishnan VK, Bhattacharya I and Vishwanatha JK: Deregulated cyclooxygenase-2 expression in oral premalignant tissues. Mol Cancer Ther 1: 1265-1271, 2002.

30. Yu HP, Xu SQ, Liu L, Shi LY, Cai XK, Lu WH, Lu B, Su YH and Li YY: Cyclo-oxygenase-2 expression in squamous dysplasia and squamous cell carcinoma of the esophagus. Cancer lett 198: 193-201, 2003

31. Tsujii M and DuBois RN: Alterations in cellular adhesion and apoptosis in epithelial cells overexpressing prostaglandin endoperoxide synthase 2. Cell 83: 493-501, 1995 .

32. Zhi H, Wang L, Zhang J, Zhou C, Ding F, Luo A, Wu M, Zhan Q and Liu Z: Significance of COX-2 expression in human esophageal squamous cell carcinoma. Carcinogenesis 27: 1214-1221, 2006.

33. Kase S, Osaki M, Honjo S, Adachi H, Tsujitani S, Kaibara N and Ito H: Expression of cyclo-oxygenase-2 is correlated with high intratumoral microvessel density and low apoptotic index in human esophageal squamous cell carcinomas. Virchows Arch 442: 129-135, 2003.
34. Quan C, Cha EJ, Lee HL, Han KH, Lee KM and Kim WJ: Enhanced expression of peroxiredoxin I and 6 correlates with development, recurrence and progression of human bladder cancer. J Urol 175: 1512-1516, 2006.

35. Lehtonen ST, Svensk AM, Soini Y, Pääkkö P, Hirvikoski P Kang SW, Säily M and Kinnula VL: Peroxiredoxins, a novel protein family in lung cancer. Int J Cancer 111: 514-521, 2004.

36. Yanagawa T, Iwasa S, Ishii T, Tabuchi K, Yusa H, Onizawa K, Omura K, Harada H, Suzuki H and Yoshida H: Peroxiredoxin I expression in oral cancer: A potential new tumor marker. Cancer Lett 156: 27-35, 2000.

37. Wen ST and Van Etten RA: The pag gene product, a stress-induced protein with antioxidant properties, is an abl $\mathrm{SH} 3$-binding protein and a physiological inhibitor of c-Abl tyrosine kinase activity. Genes Dev 11: 2456-2467, 1997.

38. Prospéri MT, Ferbus D, Rouillard D and Goubin G: The pag gene product, a physiological inhibitor of c-abl tyrosine kinase, is overexpressed in cells entering $\mathrm{S}$ phase and by contact with agents inducing oxidative stress. FEBS Lett 423: 39-44, 1998.

39. Yanagawa $T$, Omura K, Harada H, Ishii T, Uwayama J, Nakaso K, Iwasa S, Koyama Y, Onizawa K, Yusa H and Yoshida H: Peroxiredoxin I expression in tongue squamous cell carcinomas as involved in tumor recurrence. Int J Oral Maxillofac Surg 34: 915-920, 2005.

40. Richmond A: NF-kappa B chemokine gene transcription and tumour growth. Nat Rev Immunol 2: 664-674, 2002.

41. Loercher A, Lee TL, Ricker JL, Howard A, Geoghegen J, Chen Z, Sunwoo JB, Sitcheran R, Chuang EY, Mitchell JB, et al: Nuclear factor-kappaB is an important modulator of the altered gene expression profile and malignant phenotype in squamous cell carcinoma. Cancer Res 64: 6511-6523, 2004

42. Takada Y, Singh S and Aggarwal BB: Identification of a p65 peptide that selectively inhibits NF-kappa B activation induced by various inflammatory stimuli and its role in down-regulation of NF-kappaB-mediated gene expression and up-regulation of apoptosis. J Biol Chem 279: 15096-15104, 2004.

43. Wolf JS, Chen Z, Dong G, Sunwoo JB, Bancroft CC, Capo DE, Yeh NT, Mukaida N and Van Waes C: IL (interleukin)-1alpha promotes nuclear factor-kappaB and AP-1-induced IL-8 expression, cell survival and proliferation in head and neck squamous cell carcinomas. Clin Cancer Res 7: 1812-1820. 2001.

44. Bancroft CC, Chen Z, Yeh J, Sunwoo JB, Yeh NT, Jackson S, Jackson C and Van Waes C: Effects of pharmacologic antagonists of epidermal growth factor receptor, PI3K and MEK signal kinases on NF-kappaB and AP-1 activation and IL-8 and VEGF expression in human head and neck squamous cell carcinoma lines. Int J Cancer 99: 538-548, 2002.

45. Nakayama H, Ikebe T, Beppu M and Shirasuna K: High expression levels of nuclear factor kappaB IkappaB kinase alpha and Akt kinase in squamous cell carcinoma of the oral cavity. Cancer 92: 3037-3044, 2001. 